\title{
Experience- and Age-Related Outgrowth of Intrinsic Neurons in the Mushroom Bodies of the Adult Worker Honeybee
}

\author{
Sarah M. Farris, ${ }^{1}$ Gene E. Robinson, ${ }^{1,2}$ and Susan E. Fahrbach ${ }^{1,2}$ \\ ${ }^{1}$ Department of Entomology and the ${ }^{2}$ Neuroscience Program, University of Illinois at Urbana-Champaign, Urbana, \\ Illinois 61801
}

A worker honeybee performs tasks within the hive for approximately the first 3 weeks of adult life. After this time, it becomes a forager, flying repeatedly to collect food outside of the hive for the remainder of its 5-6 week life. Previous studies have shown that foragers have an increased volume of neuropil associated with the mushroom bodies, a brain region involved in learning, memory, and sensory integration. We report here that growth of the mushroom body neuropil in adult bees occurs throughout adult life and continues after bees begin to forage. Studies using Golgi impregnation asked whether the growth of the collar region of the mushroom body neuropil was a result of growth of the dendritic processes of the mushroom body intrinsic neurons, the Kenyon cells. Branching and length of dendrites in the collar region of the calyces were strongly

Postnatal changes in dendritic complexity in the mammalian brain have been correlated with increased amounts of sensory or motor experience. For example, dendrites of cortical neurons of rats reared in enriched environments are longer and more branched compared to those of rats reared alone or in typical group laboratory cages (Volkmar and Greenough, 1972; Greenough and Volkmar, 1973; Uylings et al., 1978; Kolb and Whishaw, 1998; Kolb et al., 1998). Increases in brain weight and cortical thickness that were positively correlated with rearing in an enriched environment (Diamond et al., 1972) are typically explained in terms of changes in dendrites. For example, Uylings et al. (1978) directly correlated increases in thickness of the visual cortex with increased dendritic branching and lengthening in cortical pyramidal cells.

Experience-related changes in brain structure have also been documented in insects, particularly in the mushroom bodies. In the fruit fly Drosophila melanogaster, the number of Kenyon cell axons in the mushroom bodies decreases when the adult fly is housed in conditions of olfactory deprivation or social isolation (Technau, 1984). The volume of the mushroom body neuropil of adult fruit flies is also affected by housing conditions in the

\footnotetext{
Received Jan. 3, 2001; revised May 23, 2001; accepted May 25, 2001.

This work was supported by the National Science Foundation, the National Institutes of Health, and the University of Illinois Campus Research Board. We thank Dr. Nicholas Strausfeld and Michael Zimmerman for assistance with the Golgi impregnation protocol, Dr. Elizabeth Capaldi and Allan Ross for assistance with colony setup and honeybee collection, Joseph Sullivan and Dr. Susanne Aref for statistical guidance, and Drs. William Greenough and Akira Chiba for helpful comments regarding this manuscript. Cynthia Mata, Jennifer Strande, Brendan O'Connell, Nicholas Gomes, and Elsa Arteaga provided field assistance.

Correspondence should be addressed to Sarah M. Farris, Arizona Research Laboratories Division of Neurobiology, University of Arizona, 611 Gould-Simpson Building, Tucson, AZ 85721. E-mail: farris@neurobio.arizona.edu.

Copyright (ㄷ) 2001 Society for Neuroscience $0270-6474 / 01 / 216395-10 \$ 15.00 / 0$
}

correlated with worker age, but when age-matched bees were directly compared, those with foraging experience had longer, more branched dendrites than bees that had foraged less or not at all. The density of Kenyon cell dendritic spines remained constant regardless of age or behavioral state. Older and more experienced foragers therefore have a greater total number of dendritic spines in the mushroom body neuropil. Our findings indicate that, under natural conditions, the cytoarchitectural complexity of neurons in the mushroom bodies of adult honeybees increases as a function of increasing age, but that foraging experience promotes additional dendritic branching and growth.

Key words: Apis mellifera; dendritic branching; foraging; Golgi impregnation; Kenyon cells; spine density

laboratory (Heisenberg et al., 1995). These studies suggest that adult insect brains, like adult mammalian brains, are altered in structure (and presumably in function) by changes in the environment.

Additional evidence of experience-driven plasticity in the insect mushroom bodies comes from studies of behavioral development in adult honeybees. At $\sim 3$ weeks of age, the adult worker bee switches from performing in-hive tasks to foraging (Winston, 1987; Robinson, 1992). In striking contrast to its preforaging days inside the dark hive, the foraging honeybee spends the remainder of its life bringing food to the hive. Foraging involves extended flight ( $>5 \mathrm{~min})$, learning of food locations, navigation using multiple cues, and communication via a symbolic dance language (Fahrbach and Robinson, 1995; Hammer and Menzel, 1995). Withers et al. (1993) showed that honeybee foragers have a significantly larger volume of mushroom body neuropil than 1-dold adult bees. The mushroom bodies of bees induced to forage precociously undergo a volume expansion comparable with that observed in foragers of normal age (Withers et al., 1993, 1995; Durst et al., 1994). Bees prevented from flying and bees reared entirely in the dark display increases in neuropil volume that are smaller but still significant relative to 1 -d-old bees (Withers et al., 1995; Fahrbach et al., 1998). These data suggest that increases in neuropil volume observed in the mushroom bodies have both ageand experience-related determinants.

The present study was designed to examine in the honeybee the relationships among experience, neuropil volume, and dendritic complexity. Our long-term goals are to decipher the molecular mechanisms by which experience is coupled to neuronal cytoarchitecture and to understand the adaptive significance of this phenomenon. The honeybee was selected for these investigations 
because its rich repertoire of adult behaviors can be readily studied under natural conditions.

\section{MATERIALS AND METHODS}

\section{Honeybees}

Adult worker honeybees were obtained from colonies at the Bee Research Facility of the University of Illinois at Urbana-Champaign. Colonies were maintained according to standard commercial practice. To obtain bees at day 7 of adult development $(7 \mathrm{~d}$ after pupation and $2 \mathrm{~d}$ before the emergence of the adult), a brood comb containing prepupae was removed from the colony and placed in an incubator $\left(33^{\circ} \mathrm{C},>90 \%\right.$ humidity). The prepupal stage is a quiescent period occurring immediately before the pupal molt and can be recognized by the vertical position and lack of movement of the larva in the brood cell (Bertholf, 1925; Winston, 1987). The position of all prepupae was marked on a piece of acetate laid over the comb. The comb was checked each day, and the day of the pupal molt was noted on the acetate for each bee. Seven days after the pupal molt, developing adults were collected as needed for histology. These bees will hereafter be referred to as pupal day 7 (P7) bees. Newly emerged adult honeybees were collected by removing a brood comb containing pharate adults within 1 or $2 \mathrm{~d}$ of emergence from a source colony. This comb was then placed in an incubator $\left(33^{\circ} \mathrm{C}, 90 \%\right.$ relative humidity). The comb was checked each day for adult honeybees, and 1 -d-old bees (hereafter referred to as D1 bees) were collected $<4 \mathrm{hr}$ after emergence from the brood comb. These bees were immediately dissected for histology or tagged (paint mark or number tag) and returned to the source colony.

Observations of flight behavior were always made at the hive entrance. Bees returning to the entrance with conspicuous pollen loads were designated foragers (Winston, 1987). Short flights near the hive entrance $<5 \mathrm{~min}$ in duration that were initiated facing the hive entrance were recorded as orientation flights (Capaldi et al., 2000). Flying bees used in neuroanatomical studies were collected individually at the hive entrance using a modified shop vacuum (Robinson and Page, 1988). Observations of nursing behavior were made after opening the hive. Nurse bees were identified as workers that inserted their heads into brood cells (Robinson, 1987). These bees were collected from the comb immediately after being observed performing this behavior. During dissection, observation of hypopharyngeal gland development was also used to clarify nurse and forager status. Nursing bees have well developed hypopharyngeal glands that produce brood food secretions for the feeding of bee larvae (Winston, 1987). These glands degenerate in foragers (Winston, 1987) and are noticeably smaller when observed under the dissecting microscope. Foragers and nurses that did not match these criteria were removed from the study. Individual experiments are described in more detail below.

\section{Experiment 1: changes in volume of the mushroom bodies in adult honeybees from a typical colony}

Tagging of bees and hive entrance modifications. The colony used for this experiment contained a naturally mated queen and $\sim 40,000$ adult bees. Newly emerged D1 adult bees ( $<4$ hr old) were marked on the dorsal thorax with a unique colored number tag $(n=500)$ and then returned to the colony. This colony was fitted with a glass-covered entrance ramp to improve detection of tagged bees exiting and reentering the hive. A film of petroleum jelly on the glass cover discouraged bees from walking tag side-down (Winston and Katz, 1982). Morning flight was prevented by aiming a water sprinkler (controlled by a timer) at the hive entrance from $1 \mathrm{hr}$ before sunrise until noon. This simulated rain confines bees without otherwise altering their behavior (Huang and Robinson, 1996; Capaldi et al., 2000). This was done so that the hive entrance could be monitored continuously whenever flight was possible.

Behavior observations and brain collection. The entrance was monitored from noon to sunset by at least two observers who recorded the departure and return of all tagged bees. These observations resulted in complete flight histories for individual bees. Once the entire tagged cohort of bees had initiated foraging, continuous monitoring of the hive entrance was replaced with daily spot checks to ensure that tagged foragers continued to forage. Flying bees used in neuroanatomical studies were collected individually at the hive entrance.

The groups of bees collected for estimation of the volume of the mushroom bodies were D1 bees, bees returning from their first orientation flight, bees returning from their fifth orientation flight, bees returning from their first foraging flight, bees with 1 week of foraging experience, and bees with 2 weeks of foraging experience. The median number of orientation flights taken by honeybees before foraging was five, but the range was extremely wide: 1-18 flights per bee (Capaldi et al., 2000). Therefore, bees collected on returning from their fifth flight from the hive were regarded as potential foragers. Bees were collected on the basis of flight experience rather than age for the following reason. Numerous studies have shown that a typical age at first foraging is 3 weeks, but that this age is sensitive to environmental factors (e.g., weather and nectar flow) and experimental manipulations (e.g., treatment with juvenile hormone and age distribution of workers within a colony) as well as genotype (Robinson, 1992; Huang and Robinson, 1996). In the present study, conducted under consistently fine weather conditions, the median number of days to the onset of foraging was 13 , with a range of $8-18(n=125)$

Histology and volume estimation. Collected bees were held on ice until their brains were dissected (never $>2 \mathrm{hr}$ after collection). Brains were dissected in bee saline (Huang et al., 1991) and fixed in Bouin's alcoholic fixative overnight. Tissue was dehydrated through a series of ethanols to toluene and then embedded in Paraplast (Oxford Labware, St. Louis, MO). Embedded brains were sectioned transversely at $10 \mu \mathrm{m}$. Complete sets of serial sections were mounted on Superfrost Plus slides (Fisher Scientific, St. Louis, MO). Tissue was stained with Luxol fast blue (Solvent Blue 38, Sigma S 3382; Sigma, St. Louis, MO) and cresyl violet (Sigma C 1791) using a modification of the protocol of Klüver and Barrera (1953) (Fahrbach et al., 1995). Stained slides were dehydrated in ethanol, cleared in Hemo-De (Fisher Scientific), and coverslipped with Cytoseal (Stephens Scientific, Cornwall, NJ). Neuronal cell bodies were stained bright purple, and neuropil was stained blue. The volume of the mushroom bodies (one hemisphere per brain, selected randomly) was estimated by application of the Cavalieri method to sampled sections (Gundersen et al., 1988). Mushroom body volume was estimated for 11 D1 adult bees, 16 bees captured after their first orientation flight, 12 bees captured after their fifth orientation flight, 9 bees captured after their first foraging flight, six 1 week foragers, and six 2 week foragers. Estimates of the volume of the neuropil of the mushroom bodies included the medial and lateral calyces, peduncle, $\alpha$ lobe, and $\beta$ lobe.

Sections were viewed at a magnification of $300 \times$ on a Zeiss (Thornwood, NY) microscope and drawn using a camera lucida. Slides were coded so that the person doing the drawing did not know the experimental group. One of the first six sections after the first appearance of the mushroom bodies in the set of serial sections was chosen using a random number table. From this starting point, every sixth section thereafter was drawn. This procedure met the requirement of the Cavalieri method for systematic random sampling. As in previous studies (Withers et al., 1993, 1995; Fahrbach et al., 1995), it was determined that estimates of volume based on sampling every sixth section differed by $<5 \%$ from volumes calculated using drawings of every section. Cross-sectional areas were determined by counting the number of points on a transparent $20 \mathrm{~mm}$ grid that fell within the traced boundaries of the neuropil or the Kenyon cell body regions. Point counts were converted to volume estimates for each hemisphere, taking into account sampling frequency, magnification, grid size, and section thickness. The efficacy of the Cavalieri method for volume estimation is well documented (Gundersen and Jensen, 1987; Gundersen et al., 1988; Møller et al., 1990; West, 1993). Volume estimates of sectioned tissue made using the Cavalieri method have been confirmed by fluid displacement studies (Michel and Cruz-Orive, 1988).

Data analysis. One-way ANOVA and Student-Newman-Keuls post hoc tests were performed to compare estimated regional brain volumes (SuperANOVA, version 1.11 for Macintosh; Abacus Concepts, Berkeley, CA). The correlation between flight experience and neuropil volume was further analyzed using the nonparametric Kendall test (Siegel, 1956). This rank correlation test allowed us to determine whether neuropil volume tended to increase with age, experience, or both. For this analysis, groups with differing amounts of flight experiences were arranged in order of increasing age and experience (e.g., D1 $=0$ and first flight $=1$ ). Neuropil volumes were ranked from low to high. StatView 4.5 (Abacus Concepts) was used to calculate Kendall's $\tau$ corrected for ties. Results were considered significant at $p<0.05$.

\section{Experiment 2: analysis of Golgi-impregnated Kenyon cell dendrites by age and experience}

Experimental groups. P7 pupae, D1 adults, nurses (9-10 d of age), foragers (3 weeks of age), and 4-week-old bees were collected from a typical colony unrelated to the one used in the previous experiment. Nurse bees and foragers were selected from a group of $\sim 900$ D1 adult bees paint-marked on the thorax and reintroduced to their source colony. Twenty-three days after adult emergence, paint-marked bees were first 
Table 1. Age and foraging experience of bees used for experiment $2^{a}$

\begin{tabular}{|c|c|c|c|c|c|}
\hline Behavioral group & Age (d) & Colony type & $\begin{array}{l}\text { No. of bees used in } \\
\text { Golgi analysis }\end{array}$ & $\begin{array}{l}\text { No. of neurons } \\
\text { analyzed }\end{array}$ & $\begin{array}{l}\text { No. of bees used for } \\
\text { volume estimations }\end{array}$ \\
\hline P7 & -2 & Typical & 7 & 10 & 6 \\
\hline D1 adult & 1 & Typical & 6 & 8 & 6 \\
\hline Nurse & $9-10$ & Single cohort & 5 & 11 & 6 \\
\hline New precocious forager ( $1 \mathrm{~d}$ foraging $)$ & $9-10$ & Single cohort & 6 & 8 & 6 \\
\hline Experienced precocious forager ( $2-5 \mathrm{~d}$ foraging) & $9-10$ & Single cohort & 5 & 9 & 5 \\
\hline Forager $^{b}$ & 23 & Typical & 6 & 10 & 6 \\
\hline Four-week-old ${ }^{c}$ & 30 & Typical & 7 & 16 & 6 \\
\hline
\end{tabular}

${ }^{a}$ All bees analyzed were sisters, sampled from the same source colony.

${ }^{b}$ Collected at the hive entrance carrying a pollen load.

${ }^{c}$ Collected inside the hive; likely had some foraging experience.

observed returning to the colony entrance carrying pollen. Thirty of these foragers were collected for histology. One week later, paint-marked bees with unknown amounts of foraging experience were collected inside the colony.

In previous studies, D1 adults, rather than P7 bees, have been used as the starting point for analyses of the relationship between mushroom body development and behavioral development (Withers et al., 1993, 1995; Durst et al., 1994; Fahrbach et al., 1998). Studies of the larval and pupal development of the mushroom bodies showed that neurogenesis in the honeybee mushroom bodies ends at day 5 of the pupal stage (P5; Farris et al., 1999; Ganeshina et al., 2000). Volume increases and other neuroanatomical changes in the mushroom bodies after this time thus reflect process outgrowth alone. We have therefore included samples of P7 bees in our Golgi analyses. Using P7 bees rather than D1 adults as the "ground zero" state permits a complete representation of Kenyon cell development.

Three groups of bees, all $10 \mathrm{~d}$ of age but with differing experience, were collected from a small single cohort colony (Robinson et al., 1989) containing all young bees, a queen, an empty comb for egg laying, and a single comb containing honey and pollen. This environment reliably induces precocious foraging in a subset of bees, $\sim 2$ weeks earlier than in a typical colony (Huang and Robinson, 1992; Robinson, 1992). The single-cohort colony was made up of 1200 paint-marked D1 adult bees obtained from the same colony that supplied the experimental groups described above.

Observations were made at the entrance to the single-cohort colony for $2 \mathrm{hr}$ each afternoon, beginning on the sixth day after the colony was established. Bees collected from the colony were assigned to one of the following three groups defined on the basis of behavior. Marked bees observed returning to the colony carrying pollen were paint-marked a second time on the abdomen. At $9-10 \mathrm{~d}$ of age, 30 paint-marked precocious foragers were collected from the colony. These bees were designated experienced precocious foragers. We also collected 30 pollencarrying precocious foragers with thorax paint markings only. The lack of an abdominal paint mark indicated that these bees had just begun foraging that day, and these bees were therefore designated new precocious foragers. A third group of unmarked bees observed feeding brood were collected from within the colony and designated nurses. Because nursing is a preforaging behavior, nurse bees are presumed to have no foraging experience. Analysis of precocious foragers permitted dissociation of the effects of age and experience on Kenyon cell outgrowth. We also determined whether the volume increases observed in these young bees involved changes in Kenyon cell morphology similar to those seen in older foragers from the source colony.

The relationship of dendritic morphology to increased neuropil volume also was determined. A subset of bees from each behavioral group described above was processed for cresyl violet and Luxol fast blue staining. The Cavalieri procedure described above was used to estimate the volume of all neuropils associated with the mushroom bodies; in addition, the volume of the collar region of the calycal neuropil was estimated using a $15 \mathrm{~mm}$ grid to determine the cross-sectional area. Details concerning the amount of foraging experience, age, and source of bees used for volume estimations and Golgi analysis are summarized in Table 1.

Golgi impregnation. A combined Colonnier-rapid Golgi impregnation protocol (Li and Strausfeld, 1997) was used to stain individual Kenyon cells in the mushroom bodies. After collection, adult bees were cooled in a $4^{\circ} \mathrm{C}$ refrigerator until quiet. Brains were dissected from the head capsule in a $2.5 \%$ potassium dichromate solution containing $1.3 \%$ sucrose. Dissected brains were placed in glass scintillation vials and fixed in the same solution containing $4 \%$ glutaraldehyde for $5 \mathrm{~d}$ at $4^{\circ} \mathrm{C}$ in the dark. After fixation, brains were washed three times for 15 min each in a $2.5 \%$ potassium dichromate solution. The brains were then placed in a clean vial containing 1 part $1 \%$ osmium tetroxide, 100 parts $2.5 \%$ potassium dichromate, and $1 \%$ chloral hydrate. The tissue was incubated in this solution for $5 \mathrm{~d}$ at $4^{\circ} \mathrm{C}$ in the dark. After this step, tissue was washed repeatedly in $0.75 \%$ silver nitrate and then transferred to a fresh vial and incubated in $0.75 \%$ silver nitrate for $2 \mathrm{~d}$ in the dark at $4^{\circ} \mathrm{C}$. Brains were then dehydrated through a series of ethanols and propylene oxide and embedded in Durcupan (Fluka, Buchs, Switzerland). The plasticembedded brains were cured at $60^{\circ} \mathrm{C}$ overnight before sectioning transversely at $25 \mu \mathrm{m}$ using a tungsten carbide $\mathrm{C}$ microtome knife. The sections were mounted on Superfrost Plus slides (Fisher Scientific) and coverslipped with Cytoseal (Stephens Scientific).

Analysis of Kenyon cell arborizations. Only Kenyon cell arborizations in the collar of the calycal neuropil (see Anatomy of the honeybee mushroom bodies below) were analyzed in this study. The collar was selected for the following reasons. The collar is the largest subdivision of the caly $x$ neuropil in the honeybee mushroom bodies. An increase in volume of the collar in foraging honeybees would therefore account for a proportionally large amount of the total volume increase of the calyx. Volume changes also occur in the basal ring and lip, but both of these subdivisions are smaller than the collar and have a correspondingly proportionally smaller volume increases in foragers (Durst et al., 1994; Withers et al., 1995). In addition, the Kenyon cell population of the honeybee is heterogeneous, and no complete description of these neurons has been published. We therefore restricted our analysis to a single subdivision to ensure repeated sampling of the same population of Kenyon cells across individuals.

The stochastic nature of the Golgi impregnation process allowed us to randomly sample Kenyon cells across the brains of all 30 bees collected from each behavioral group. Golgi-impregnated neurons in the collar were selected for analysis only if all branches could be clearly discerned from surrounding stained cells and the dendritic arbor was contained within one $25 \mu \mathrm{m}$ section. A single brain typically contained zero to five cells that met these criteria. In brains that contained Kenyon cells suitable for analysis, one to four neurons were sampled. Overall, four neurons were sampled in a total of 2 bees, three neurons were sampled in 6 bees, two neurons were sampled in 12 bees, and one neuron was sampled in 22 bees. Bees with differing numbers of neurons sampled were distributed evenly throughout all of the behavioral groups.

A camera lucida attached to a Zeiss microscope was used to trace the dendritic trees of individual collar Kenyon cells in Golgi-stained brains at a $2250 \times$ total magnification. All drawings and subsequent branching and length analyses were performed blind with respect to the group identity.

Branching complexity. Invertebrate neurons differ from most vertebrate neurons in that the neuronal somata are typically contained in a compartment separate from the neuropil (Bullock and Horridge, 1965; Burrows, 1996). Each soma sends a single neurite into the corresponding neuropil, where dendrites and axons branch off from the neurite. Invertebrate axons and dendrites do not arise directly from the cell body (Bullock and Horridge, 1965). Branch orders were therefore determined 
in relation to the number of branches from the main neurite rather than to the number of branches from the cell body. This approach is similar to the assignment of branch orders to dendrites arising from the apical dendrite of a pyramidal cell in the mammalian cortex (Greenough and Volkmar, 1973). To estimate the branching complexity of each Kenyon cell, branch order analysis was performed for each tracing. To determine branch order of individual dendrites, the first segment to branch off from the main neurite was labeled 1. If the dendrite branched again, those next segments were labeled 2 and so on until the end of the dendritic branch was reached. The number of dendritic segments of a given branch order was then compared among experimental groups. The total number of dendritic segments per neuron was also calculated (by summing the number of identified branches), providing a measurement of the total extent of branching in each dendritic arbor.

Sholl analysis. Dendritic length was analyzed using a Sholl analysis (Sholl, 1953). A series of concentric circles spaced at $22.5 \mathrm{~mm}$ intervals (10 $\mu \mathrm{m}$ of tissue) was printed on a piece of acetate. As described above for the assignment of dendritic branch order, the neuronal cell body could not be used as a reference point at the center of the dendritic field. Instead, the center of the Sholl diagram was placed at the point at the base of the neurite where the first large dendrite branches arise. The number of segments that crossed each consecutive circle was counted to estimate how many segments of a given length are present in each neuron.

Spine counts. Dendritic spine density was estimated in D1 adults, nurses, experienced precocious foragers, and typical foragers. P7 bees were not included in this analysis, because there are significant morphological differences between the spines of pupal and adult bees (see Results, Appearance of the dendritic arborizations of collar Kenyon cells in bees of different ages). To keep the area of sampling constant between different groups, only segments between 20 and $30 \mu \mathrm{m}$ from the main branch point (as determined using the Sholl ring diagram) were used for this analysis. This corresponds roughly to the center of the dendritic tree. For each neuron, three straight segments residing primarily within a single level of focus were projected onto a piece of paper using a camera lucida. A $22.5 \mathrm{~mm}$ wide box (corresponding to $10 \mu \mathrm{m}$ ) was aligned over the dendritic segment, and the number of spines occurring within the confines of the box was recorded. Spines were defined as a protuberance from the dendritic branch. This included all three morphological types of spines observed in the Kenyon cells of adult bees, as described in Results. Two dendritic arbors from three brains were analyzed for each behavioral group.

Statistical analysis of Golgi measures. Comparisons of spine density, Sholl ring measurements, branch orders, and dendritic segment numbers between the experimental groups were performed with SuperANOVA software, version 1.11 for Macintosh (Abacus Concepts) and SAS Institute (Cary, NC) software. For all parameters measured, all behavioral groups were first compared within a single ANOVA, and when significant, pairwise comparisons of all groups were performed. One-way ANOVA was performed for all groups collected on the measures of neuropil volume, spine density, and total number of dendritic segments. Bees from the single-cohort colony were compared directly with those from the source colony because of their identical genetic background. Previous studies (Withers et al., 1993) have shown that typical age nurses collected from both colony types have comparable mushroom body volumes, indicating that there are no colony effects on this aspect of mushroom body neuroanatomy. If a significant result was obtained for the ANOVA $(p<0.05)$, pairwise group comparisons were then made using Fisher's protected least significant difference (LSD). Because of the interdependence of consecutive measures of branch order and Sholl ring intersections (e.g., there can be no sixth-order branches if there are no fifth-order branches), branch order and Sholl ring intersection distributions were each analyzed by two-way ANOVA. In each test, all of the consecutive measurements for either branch order or Sholl ring intersections were combined. All overall two way ANOVA results were statistically significant $(p<0.05)$, and a least square means comparison was used to determine which groups differed significantly from each other. All pairwise comparisons were considered significant at $p<0.05$.

\section{Anatomy of the honeybee mushroom bodies}

Several detailed neuroanatomical descriptions of the mushroom bodies of the honeybee have been published (Mobbs, 1982; Farris et al., 1999). Briefly, the honeybee mushroom bodies are paired structures located in the protocerebrum (Fig. 1). The mushroom body of each hemisphere consists of two cup-shaped afferent input zones (medial and lateral calyx)

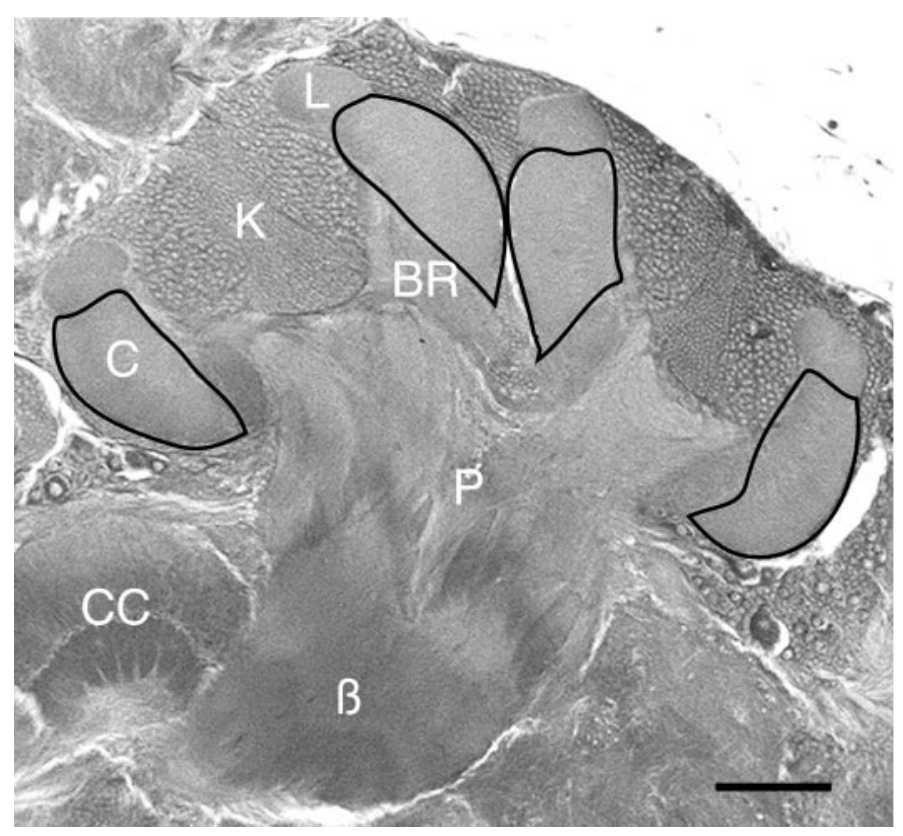

Figure 1. The mushroom bodies of the adult bee. Kenyon cell somata $(K)$ occupy a region entirely distinct from the neuropil. Kenyon cell axons make up the pedunculus $(P)$ and the lobes [only the $\beta$ lobe $(\beta)$ is seen in this view]. Kenyon cell dendrites form the calyx, which is subdivided into three regions, the lip $(L)$, collar $(C)$, and basal ring $(B R)$. Dendrites of the collar region only (outlined) were analyzed in this study. $C C$, Central complex. Scale bar, $100 \mu \mathrm{m}$.

that contain the dendritic projections of the intrinsic neurons (Kenyon cells). Each calyx can be subdivided into three major regions defined by morphology and afferent input type. The lip receives olfactory information from projection neurons of the antennal lobe; the collar receives visual input from the optic lobes; and the basal ring receives a mixture of visual and olfactory inputs (Mobbs, 1982). Kenyon cell somata reside primarily within the calyx cup, although some are found lining the outer surfaces of the calyces. Kenyon cell axons from each calyx merge as they travel through a pedunculus at the base of the calyces. The axons then bifurcate so that each Kenyon cell innervates two lobes ( $\alpha$ and $\beta$ ), which make efferent connections with other protocerebral neurons.

\section{RESULTS}

\section{Increase in volume of the mushroom body neuropil during flight development in a typical colony}

Expansion of the neuropil of the mushroom bodies was noted as bees took their first flights (Fig. 2), and the overall ANOVA indicated differences among the groups for neuropil volume $(F=$ $13.3 ; p=0.0001)$. Only bees with 2 weeks of foraging experience, however, had a neuropil volume significantly larger than that of any other group (Student-Newman-Keuls test, $p<0.01$ ). Increased flight experience was positively correlated with neuropil volume (Kendall's $\tau$ corrected for ties $=0.42 ; p<0.0001$ ). This correlation remained significant even with the bees with 2 weeks of foraging experience omitted (Kendall's $\tau$ corrected for ties $=$ $0.31 ; p=0.001)$. This analysis suggests that there is a gradual expansion of the neuropil of the mushroom bodies during the early adult life of the worker bee. Note, however, that age and flight experience are positively correlated in this sample of worker honeybees as in any typical colony.

\section{Appearance of the dendritic arborizations of collar Kenyon cells in bees of different ages}

Kenyon cell dendritic arbors in the collar region of the calyx were typically fan- or brush-shaped (Fig. 3). Two types of dendritic 


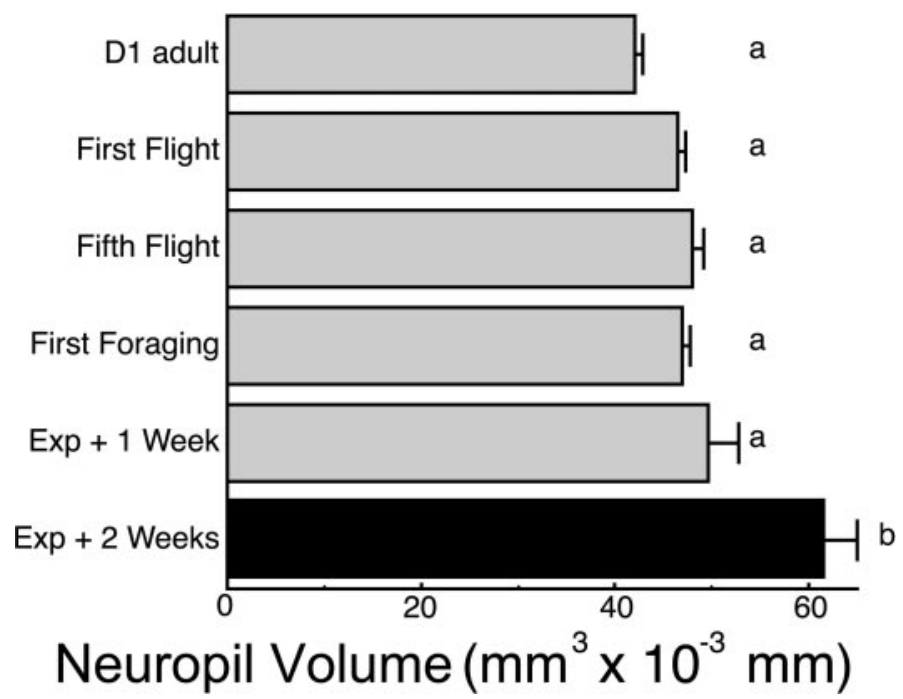

Figure 2. Ontogeny of mushroom body neuropil volume increase in bees taken from a typical colony. An increase in neuropil volume is positively correlated with increasing age and experience (Exp). Sample sizes for each group are as follows: day 1 adult, $n=11$; first orientation flight, $n=$ 16; fifth orientation flight, $n=12$; first foraging flight, $n=9$; 1 week forager, $n=6$; and 2 week forager, $n=6$. Letters indicate significant differences between groups as indicated by post hoc comparison (StudentNewman-Keuls test). Groups assigned the same letters are statistically similar to each other.

segments were observed. The majority projected downward into the collar neuropil from a single main branch point from the neurite, which resembled the crotch of a tree. Other segments arose above the main branch point, closer to the cell body, and projected perpendicular to the main neurite. This division is particularly clear in the dendritic tree shown in Figure $3 C$.

Collar dendrites appeared more blunt and compact in pupal and young adult bees (Fig. 3A,B), and elongated and spread out in older bees (Fig. 3C,D). Dendritic trees of older bees also appeared more densely branched than those of younger bees.

Dendritic spines were clearly visible along the length of Kenyon cell dendrites. There was a noticeable change in the morphology of dendritic spines at the time of adult emergence (Fig. 4). Collar Kenyon cell dendrites of P7 bees had many long, filamentous spines along their length, interspersed with a few shorter spines (Fig. $4 A$ ). Dendrites of D1 and older adults presented predominantly shorter, thicker spines (Fig. $4 B$ ). This shorter spine morphology was retained through the remainder of adult life.

Three general types of dendritic spines were observed on Kenyon cell dendrites of adult bees. Knobbed spines resembled pinheads, consisting of a stalk arising from the dendrite topped with a distinct knob. Tooth-like spines appeared as small bumps on the surface of the dendrite, without a distinct knob at the apex. These two groups were not always entirely distinct from each other, however, because longer spines without knobbed ends were also observed. Branched spines consisted of two or three knobbed or tooth-like spines arising from a single stalk. These were differentiated from dendritic branches by their short length and small number of spines.

The relative significance of the different spine morphologies described above is unknown. Therefore, all types of spines (knobbed, tooth-like, and branched) were counted for spine density calculations. No significant differences in dendritic spine density were observed between D1 adults (mean \pm SD, $10.28 \pm$
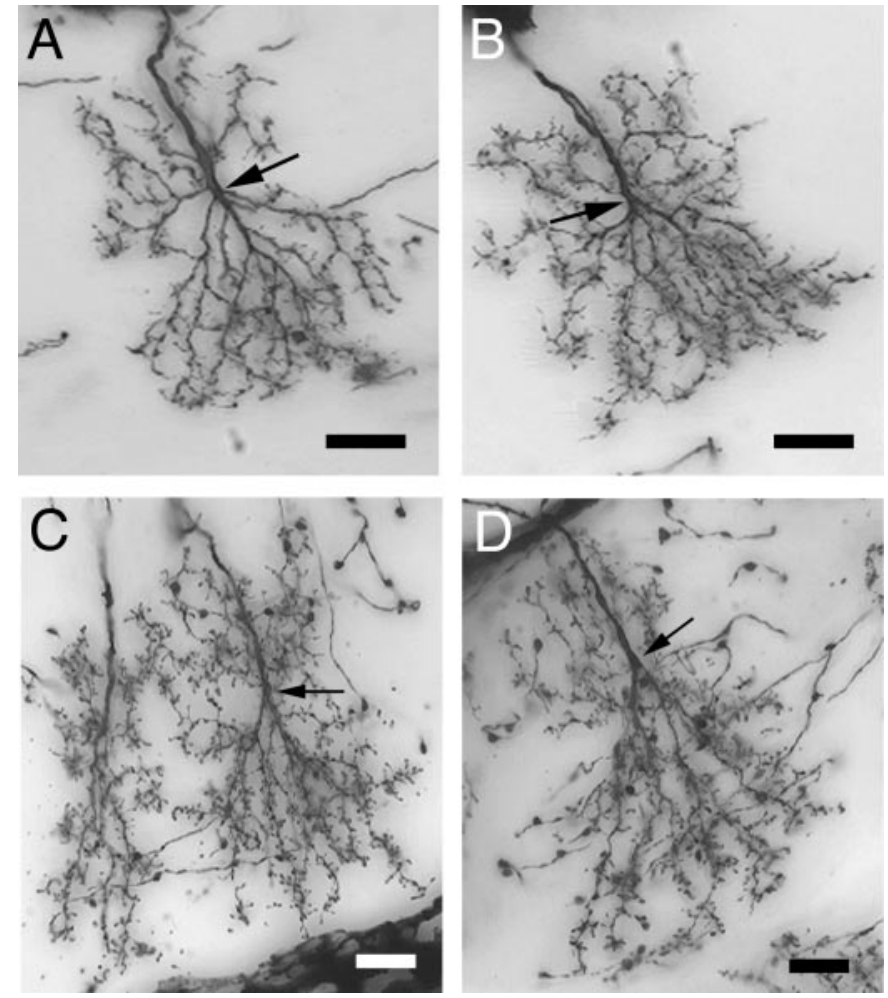

Figure 3. Golgi-stained dendritic arbors of collar Kenyon cells in bees of different ages. $A, B$, Kenyon cell dendrites in $\mathrm{P} 7$ bees. $C$, $D$, Kenyon cell dendrites in 4-week-old adults. Dendrites of older bees were typically longer and more spread out than those of pupae. The main branch point of each dendritic tree is clearly visible as a sudden termination of the main neurite (arrows). Scale bar, $10 \mu \mathrm{m}$.

2.14), nurses (9.22 \pm 1.48$)$, experienced precocious foragers $(9.56 \pm 1.65)$, and foragers $(10.28 \pm 1.64)$ [total one-way ANOVA $(\mathrm{df}=3,68), F=1.67 ; p=0.18]$. Bees in all groups had $\sim 9-10$ spines per $10 \mu \mathrm{m}$ of dendritic length.

\section{Age and experience effects on neuropil volume and dendritic morphology}

Bees of different ages and flight experience had significantly different total neuropil volumes [one-way ANOVA ( $\mathrm{df}=6,34)$, $F=29.88 ; p<0.0001$ ], collar neuropil volumes [one-way ANOVA ( $\mathrm{df}=6,34), F=22.036 ; p<0.0001]$, and numbers of dendritic segments [one-way ANOVA $(\mathrm{df}=6,65), F=6.207 ; p<$ 0.0001]. Significant differences between behavioral groups were also detected for branch order distribution [two-way ANOVA $(\mathrm{df}=55,520), F=7.50 ; p<0.0001]$ and distribution of Sholl ring intersections [two-way ANOVA (df = 34, 325), $F=23.64$; $p<$ 0.0001]. Age effects on neuropil volume and dendritic outgrowth in the mushroom bodies were best illustrated by comparing P7 bees with 4-week-old bees, which lie at the extremes of the age distribution studied. P7 bees had significantly smaller total neuropil and collar neuropil volumes than 4-week-old bees (Fisher's protected LSD, $p<0.0001$; Fig. 5). P7 bees also had significantly fewer dendritic segments (Fisher's protected LSD, $p<0.0001$; Fig. 6) and significantly fewer dendrites reaching 30, 40, and 50 $\mu \mathrm{m}$ from the main neurite than did 4-week-old bees (least square means test: $30 \mu \mathrm{m}, p<0.0001 ; 40 \mu \mathrm{m}, p<0.0001 ; 50 \mu \mathrm{m}, p<$ 0.02; Fig. 7; Table 2). Finally, P7 bees had fewer fifth-, sixth-, seventh-, and eighth-order dendritic branches than did 4-week-old bees (least square means test: fifth, $p<0.02$; sixth, $p<0.0001$; 

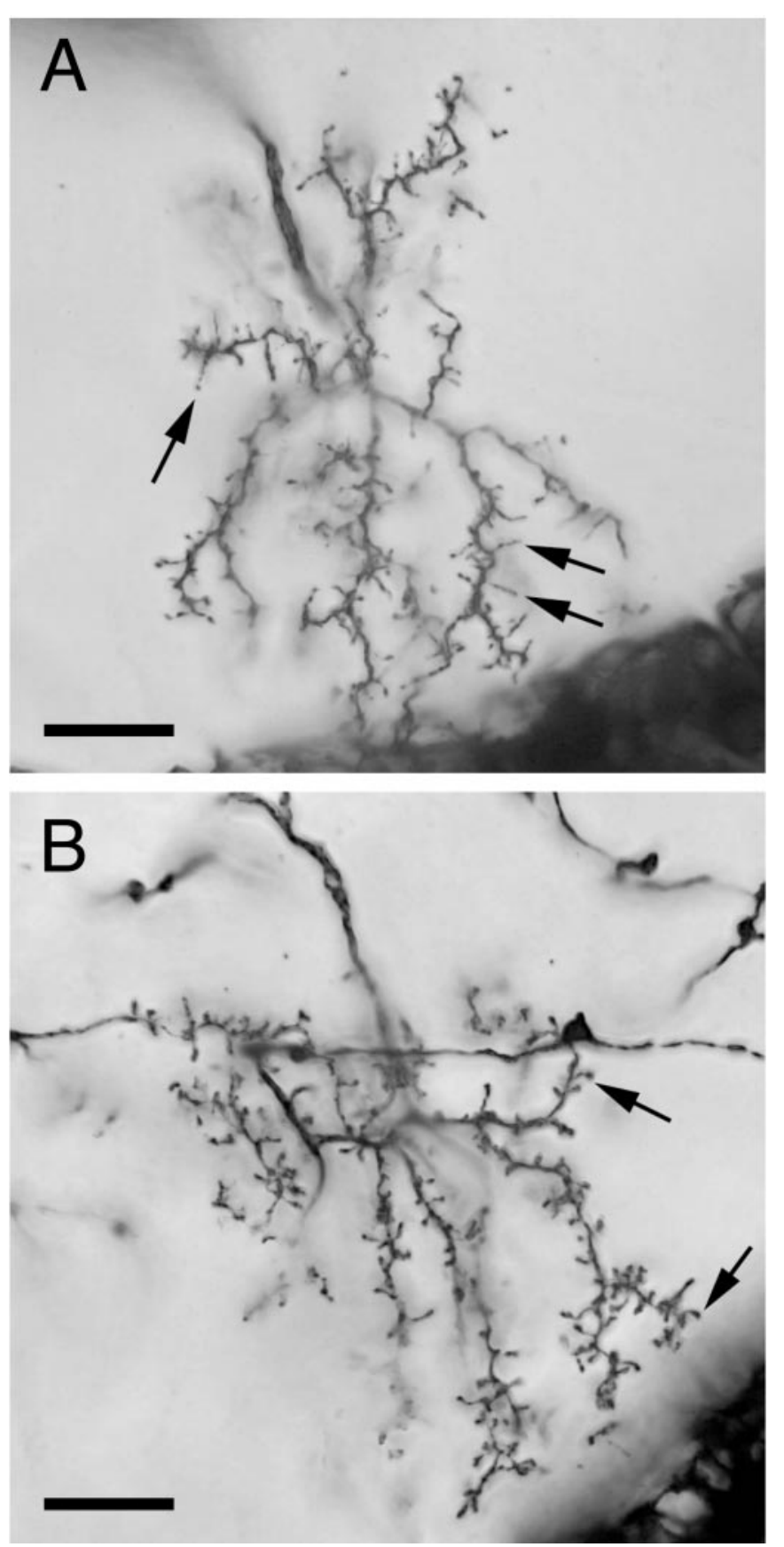

Figure 4. Differences in dendritic spine morphology between $\mathrm{P} 7$ bees and D1 adults. $A$, Dendritic spines on pupal Kenyon cell dendrites are thin and filamentous (arrows). B, Kenyon cell dendritic spines of D1 adults. The spines appear shorter and thicker, and many have a knobbed shape (arrows). Scale bar, $10 \mu \mathrm{m}$.

seventh, $p<0.003$; eighth, $p<0.0001$; Table 3). The striking difference between Kenyon cell dendrites in the $\mathrm{P} 7$ and the 4-week-old adults was also visible in Figure 3 [compare $A, B(\mathrm{P} 7)$ with $C, D$ (4-week-old adult)]. Together, these data indicate that a significant amount of neuropil expansion and dendritic branching and lengthening occurs in Kenyon cells between pupation and 4 weeks of adult life.

Effects of experience on neuropil volume and dendritic outgrowth were indicated by the comparison among nurses, new precocious foragers, and experienced precocious foragers. All three behavioral groups were collected from the single-cohort colony at the exact same age; they differed only in amount of foraging experience. Nurses had a significantly smaller total neuropil volume than new precocious foragers (Fisher's protected LSD, $p<0.05$ ) but were not different from experienced precocious foragers (Fig. 5). The two precocious forager groups did not differ in this measure. All groups had significantly increased neuropil volume with respect to D1 adults and P7 bees (Fisher's protected LSD, $p<0.001)$. The three single-cohort colony groups did not differ in collar neuropil volume, which was also larger than that of younger bees (Fisher's protected LSD, $p<0.005$ ). Experienced precocious foragers, however, had significantly more dendritic segments than did the groups with less foraging experience (Fisher's protected LSD, $p<0.001$ for nurses; $p<0.04$ for new precocious foragers), which were statistically indistinguishable from day 7 pupae (Fig. 6).

Both groups of precocious foragers had more dendritic segments reaching 20 and $30 \mu \mathrm{m}$ from the main neurite than nurses (least square means test, $p<0.003$ for new foragers; $p<0.04$ for experienced precocious foragers). New precocious foragers were more similar to nurses in having a smaller number of segments reaching $40 \mu \mathrm{m}$ from the main neurite (Fig. 7). The most dramatic effects of experience were seen using the measure of branch order (Fig. 8). New precocious foragers had significantly more third-order branches than experienced precocious foragers (least square means test, $p<0.05$ ) and significantly more fourth-order branches than nurses (least square means test, $p<0.02$ ). From the fifth order onward, new precocious foragers were indistinguishable from nurses. Experienced precocious foragers displayed a highly significant increase in higher-order branching. These data indicate that foraging experience had a large effect on Kenyon cell dendritic outgrowth in the mushroom bodies.

Examination of the dendritic trees of new and experienced precocious foragers revealed that the former tended to have more dendrites branching directly off the main neurite than did nurses or experienced precocious foragers (Fig. 9). These branches extended perpendicularly from the main neurite and sent few if any branches toward the base of the calyx (also see Fig. 3). Dendrites sprouting from the main branch point off the neurite most often extended parallel to the neurite, downward into the neuropil. These dendrites appeared to be increasingly more dense in experienced precocious foragers, indicating increased branching in this region (Fig. 9). The observed differences in dendritic organization around the neurite may account for the different branch order patterns observed in new and experienced precocious foragers (Fig. 10).

The dendritic trees of the older, more experienced bees were characterized by increased numbers of higher-order branches. Figure $8 B$ is a comparison of the branch order distribution of nurses and foragers. Foragers displayed a significant increase in the number of segments of the highest branch orders relative to nurses (least square means test: seventh order, $p<0.05$; eighth order, $p<0.003)$. This same pattern was observed in experienced precocious foragers (Fig. $8 A$ ) and 4-week-old bees (Table 3 ). These groups, however, typically showed an increase in the number of segments of intermediate branch orders (fifth and sixth) that was not observed in foragers (least square means test: fifth order, $p<0.02$ for experienced precocious foragers; $p<0.05$ for 4-week-old bees; sixth order, $p<0.08$ for experienced precocious foragers; $p<0.01$ for 4 -week-old bees). This may be a result of increased foraging experience by experienced precocious foragers and 4-week-old bees relative to 3-week-old foragers.

D1 adults had more highly branched dendrites than would be 


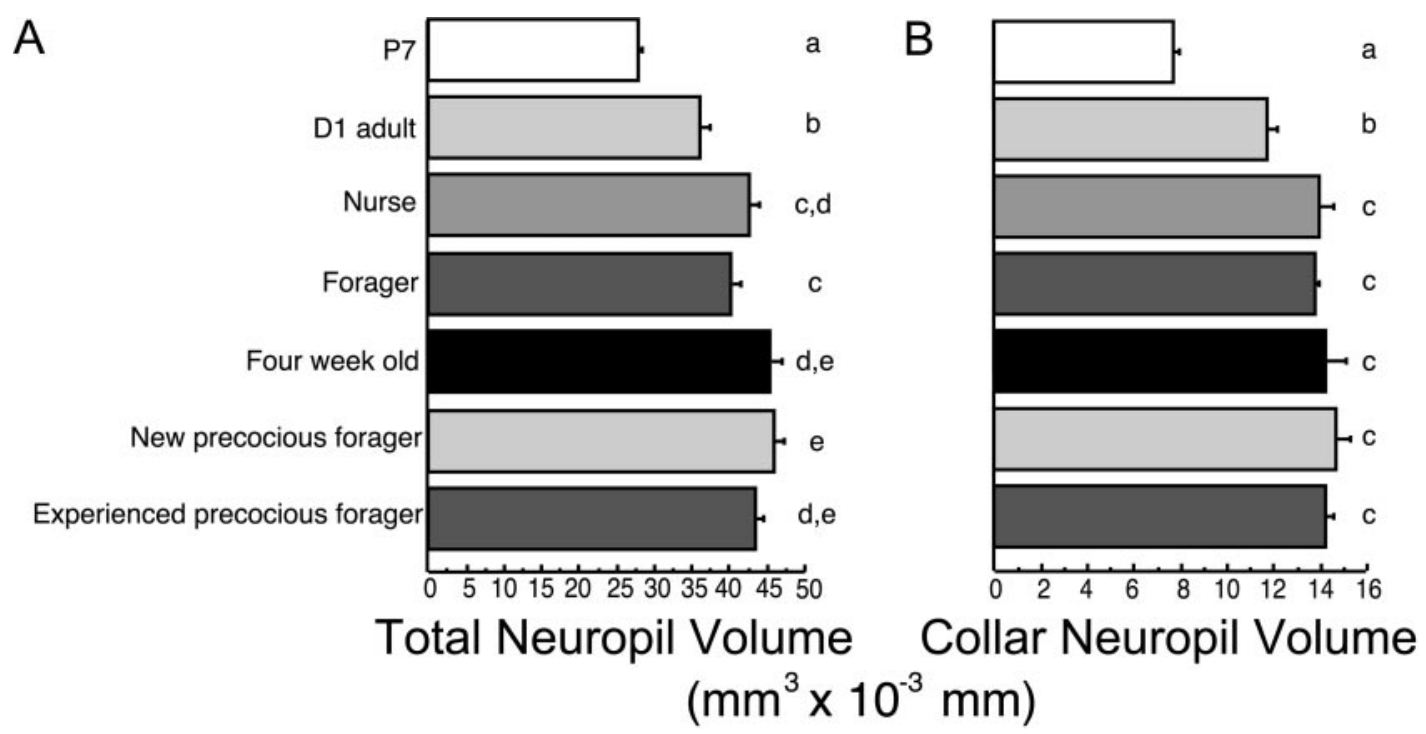

Figure 5. Mushroom body total neuropil and collar neuropil volume estimates for honeybees of differing ages and experience. The first five groups are arranged in each graph in order of increasing age, with the bottom two bars representing groups of the same age and differing amounts of foraging experience. $A$, Total volume of the mushroom body neuropil, including the collar region of the calyx. $B$, Volume of the collar region of the mushroom bodies only. Sample sizes for each behavioral group are listed in Table 1. Letters indicate significant differences in neuropil volume between groups as determined by post hoc pairwise comparisons (Fisher's protected LSD). Groups assigned the same letters are statistically similar to each other.

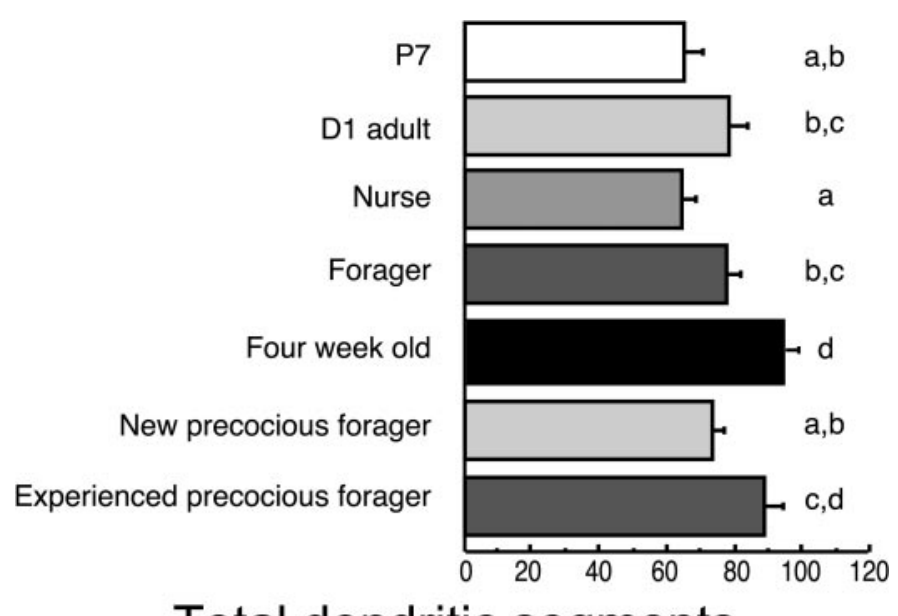

\section{Total dendritic segments}

Figure 6. Total number of dendritic segments in the collar Kenyon cells of bees of differing ages and experience. Sample sizes for each behavioral group are listed in Table 1. Groups and statistical analysis are as in Figure 5.

predicted on the basis of the branching patterns of $\mathrm{P} 7$ bees and nurses (Fig. 6, Tables 2, 3). In both branch order distribution and total number of dendritic segments, D1 adults were more similar to older, foraging-experienced bees than to other younger, inexperienced bees. Because nurses from the same source colony had less developed branch patterns more similar to those of P7 bees, it appeared that the increased branching observed in D1 adults disappeared by $10 \mathrm{~d}$ of age, only to reappear in experienced and older bees.

\section{DISCUSSION}

This study provides the first combined analysis of the effects of age and experience on neuropil volume and dendritic outgrowth in an invertebrate. Increasing age and foraging experience were associated with an increase in dendritic complexity of mushroom body intrinsic neurons. Kenyon cell dendritic trees were longer

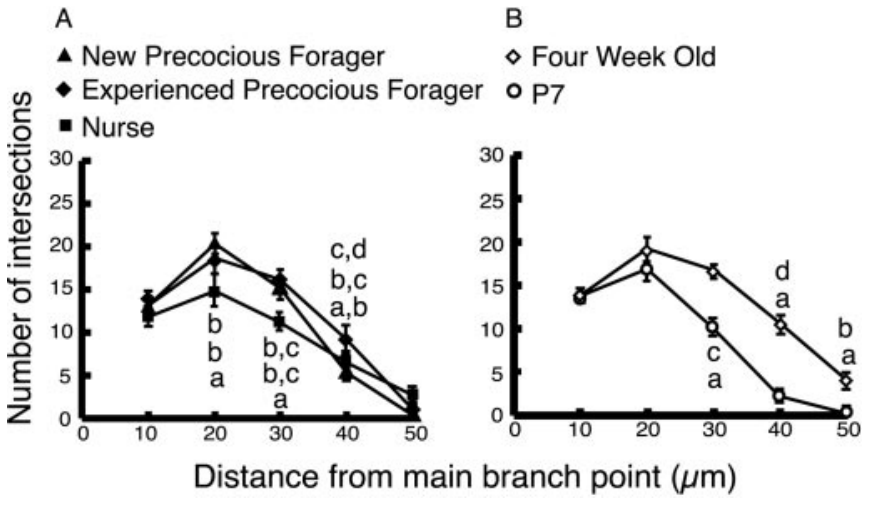

Figure 7. Age- and experience-related changes in the distribution of intersections with the Sholl ring diagram in bees. $A$, Comparison of three groups of same-age bees differing only in the amount of flight experience. $B$, Comparison of very young $(P 7)$ bees with very old (Four Week Old) bees. Sample sizes for each behavioral group are listed in Table 1. Letters indicate significant differences in segment number observed over all groups for each $10 \mu \mathrm{m}$ interval, as determined by post hoc pairwise comparisons (least square means comparisons). Groups assigned the same letters are statistically similar to each other.

and more branched in some, but not all, behavioral groups with increased mushroom body neuropil volumes. This indicates that growth of Kenyon cell dendrites is a candidate contributor to the neuropil volume increases observed in experienced foragers and older bees but is not the only determinant.

The present results indicate that neuropil volume expansion in the mushroom bodies is an ongoing process during honeybee behavioral development, initiated before the onset of foraging. These results confirm and extend past observations. An enlarged mushroom body neuropil in foragers relative to younger bees has been found in every study conducted of regional brain volumes in the adult honeybee brain (Withers et al., 1993, 1995; Durst et al., 1994; Farris et al., 1995).

In the present study there were two groups in which increased 
Table 2. Sholl ring intersection distribution of Kenyon cell dendrites

\begin{tabular}{|c|c|c|c|c|c|}
\hline \multirow[b]{2}{*}{ Behavioral group } & \multicolumn{5}{|l|}{ Distance } \\
\hline & $10 \mu \mathrm{m}$ & $20 \mu \mathrm{m}$ & $30 \mu \mathrm{m}$ & $40 \mu \mathrm{m}$ & $50 \mu \mathrm{m}$ \\
\hline P7 & $13.70 \pm 1.36$ & $16.80 \pm 1.68^{a, b}$ & $10.00 \pm 1.17^{a}$ & $2.20 \pm 0.90^{a}$ & $0.20 \pm 0.20^{a}$ \\
\hline D1 adult & $11.88 \pm 1.40$ & $14.75 \pm 1.11^{a}$ & $12.50 \pm 1.18^{a, b}$ & $7.13 \pm 1.88^{b, c}$ & $1.75 \pm 0.77^{a, b}$ \\
\hline Nurse & $11.82 \pm 1.21$ & $14.91 \pm 1.86^{a}$ & $11.09 \pm 1.11^{a}$ & $6.55 \pm 1.28^{b, c}$ & $2.64 \pm 0.95^{a, b}$ \\
\hline New precocious forager & $13.25 \pm 0.94$ & $20.38 \pm 1.22^{b}$ & $15.25 \pm 1.36^{b, c}$ & $5.25 \pm 0.84^{a, b}$ & $0.38 \pm 0.18^{a}$ \\
\hline Experienced precocious forager & $13.22 \pm 1.78$ & $18.67 \pm 1.74^{b}$ & $16.11 \pm 1.20^{b, c}$ & $9.11 \pm 1.73^{c, d}$ & $1.00 \pm 0.53^{a, b}$ \\
\hline Forager & $11.40 \pm 0.87$ & $18.80 \pm 1.76^{b}$ & $13.20 \pm 1.38^{a, b}$ & $8.00 \pm 0.96^{b-d}$ & $1.50 \pm 0.70^{a, b}$ \\
\hline Four-week-old & $13.81 \pm 1.24$ & $19.13 \pm 1.60^{b}$ & $16.63 \pm 1.41^{c}$ & $10.50 \pm 1.53^{d}$ & $4.06 \pm 1.34^{b}$ \\
\hline
\end{tabular}

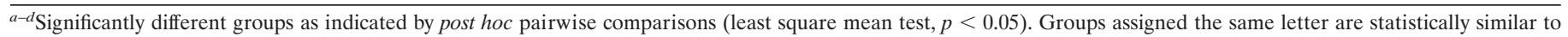
each other.

Table 3. Branch order distribution of Kenyon cell dendrites

\begin{tabular}{|c|c|c|c|c|c|c|c|c|}
\hline \multirow{2}{*}{$\begin{array}{l}\text { Behavioral } \\
\text { group }\end{array}$} & \multicolumn{8}{|c|}{ Branching order } \\
\hline & 1 & 2 & 3 & 4 & 5 & 6 & 7 & $8+$ \\
\hline P7 & $4.20 \pm 0.49$ & $8.10 \pm 1.11$ & $12.20 \pm 1.45^{a, b}$ & $13.40 \pm 1.22^{a}$ & $11.50 \pm 1.49^{a}$ & $7.80 \pm 1.33^{a}$ & $4.80 \pm 1.162^{a, b}$ & $3.60 \pm 1.86^{a}$ \\
\hline D1 adult & $3.88 \pm 0.67$ & $7.25 \pm 1.25$ & $9.38 \pm 1.21^{a}$ & $13.25 \pm 1.13^{a}$ & $13.50 \pm 1.07^{a, b}$ & $13.38 \pm 1.78^{b, c}$ & $9.38 \pm 2.10^{c}$ & $8.00 \pm 2.80^{b}$ \\
\hline Nurse & $4.36 \pm 0.58$ & $7.73 \pm 1.04$ & $11.46 \pm 1.34^{a, b}$ & $12.55 \pm 1.47^{a}$ & $11.73 \pm 1.13^{a}$ & $8.73 \pm 1.03^{a}$ & $3.91 \pm 0.84^{a}$ & $3.64 \pm 1.85^{a}$ \\
\hline New precocious & & & & & & & & \\
\hline $\begin{array}{l}\text { forager } \\
\text { Experienced } \\
\text { precocious }\end{array}$ & $6.25 \pm 0.65$ & $10.63 \pm 0.94$ & $15.00 \pm 1.68^{b}$ & $18.13 \pm 1.36^{b}$ & $12.88 \pm 2.01^{a, b}$ & $6.50 \pm 1.40^{a}$ & $2.75 \pm 1.05^{a}$ & $2.13 \pm 1.40^{a}$ \\
\hline forager & $3.67 \pm 0.47$ & $6.33 \pm 0.707$ & $10.33 \pm 0.87^{a}$ & $14.78 \pm 1.91^{a, b}$ & $18.00 \pm 1.99^{c}$ & $14.11 \pm 1.36^{b, c}$ & $10.33 \pm 2.20^{c}$ & $11.11 \pm 3.32^{b}$ \\
\hline Forager & $4.00 \pm 0.42$ & $7.70 \pm 0.746$ & $11.50 \pm 0.62^{a, b}$ & $12.80 \pm 0.85^{a}$ & $12.50 \pm 1.34^{a}$ & $10.30 \pm 1.17^{a, b}$ & $8.00 \pm 1.31^{b, c}$ & $9.90 \pm 3.21^{b}$ \\
\hline Four-week-old & $4.19 \pm 0.61$ & $8.50 \pm 1.39$ & $11.50 \pm 1.29^{a, b}$ & $14.25 \pm 1.63^{a, b}$ & $16.31 \pm 1.50^{b, c}$ & $15.31 \pm 1.35^{c}$ & $10.69 \pm 1.96^{c}$ & $11.00 \pm 4.03^{b}$ \\
\hline
\end{tabular}

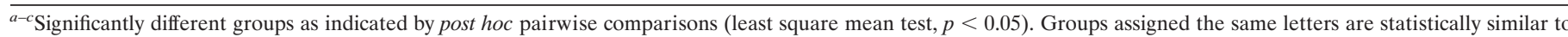
each other.

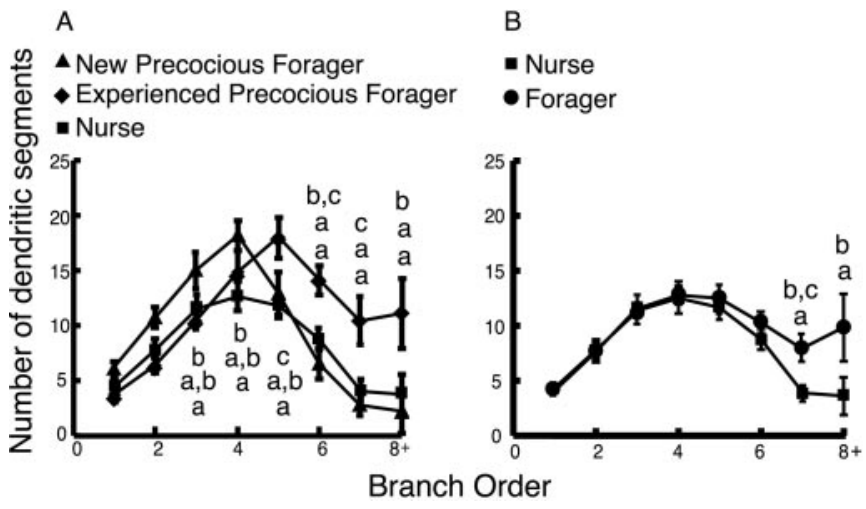

Figure 8. Distribution of dendritic branch order for bees of differing ages and experience. $A$, Comparison of three groups of same-age bees differing only in flight experience. $B$, Comparison of young, inexperienced bees (Nurse) with older, experienced bees (Forager). Sample sizes for each behavioral group are listed in Table 1. Letters indicate significant differences in segment number for each branch order as determined by post hoc pairwise comparisons (least square means comparison). Groups assigned the same letters are statistically similar to each other.

neuropil volume was not associated with dendritic outgrowth: normal-age nurses and new precocious foragers. In contrast, experienced precocious foragers of the same age displayed both neuropil volume expansion and dendritic outgrowth. Previous experiments in which bees were prevented from foraging (Withers et al., 1995) or reared in the dark (Fahrbach et al., 1998) showed that even in bees deprived of foraging and visual expe- rience, an increase in mushroom body neuropil volume is observed. Thus, the neuropil expansion observed in adult bees is a two-part process. The first phase appears primarily to be a result of a developmentally programmed growth of the processes of extrinsic neurons into the mushroom bodies, because no significant Kenyon cell dendritic outgrowth is occurring at this time. The second phase is the expansion of Kenyon cell processes, possibly as a direct result of flight or foraging experience, or both. The relative importance of the contributions of age and experience to the final morphology of the mushroom bodies of the adult honeybee has not yet been determined.

Our results indicate that experience has a pronounced effect on the honeybee brain. A progression of changes in dendritic trees occurs with increased foraging experience. The differences in dendritic trees of nurses and new and experienced precocious foragers suggest a possible scenario for dendritic outgrowth and branching in collar Kenyon cells. New dendrites appear to sprout from the main neurite at the onset of foraging experience. As foraging experience increases, the new dendrites may then send branches parallel to the main neurite, causing the main branch point to shift upward. Branching at dendritic tips also occurs during the acquisition of foraging experience. Increased dendritic branching in response to an enriched environment (Volkmar and Greenough, 1972; Greenough and Volkmar, 1973; Uylings et al., 1978) or training experience (Spinelli et al., 1980; Greenough et al., 1985; Kolb and Whishaw, 1998) is characteristic of mammalian neurons.

Experienced precocious foragers $10 \mathrm{~d}$ of age strikingly resembled 4-week-old bees in all measures of dendritic complexity. Increased branching at the distal tips of dendrites was a charac- 


\section{Nurses}
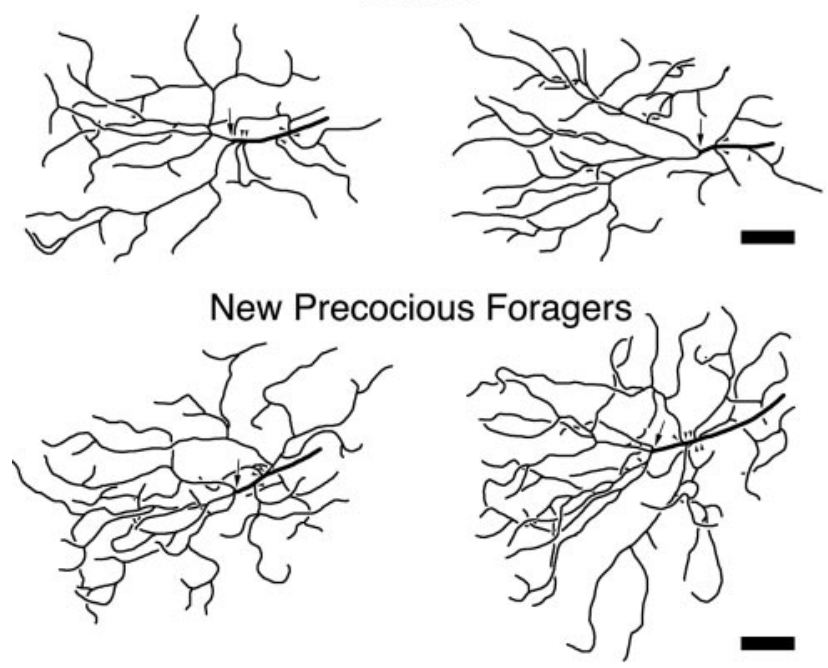

Experienced Precocious Foragers
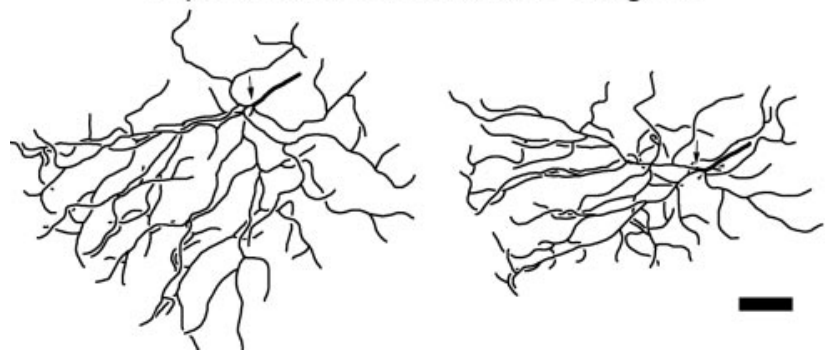

Figure 9. Representative dendritic trees of nurses, new precocious foragers, and experienced precocious foragers. Large arrows indicate the main branch point; small arrows show dendritic branches arising directly from the neurite, before the main branch point. Scale bar, $10 \mu \mathrm{m}$.

teristic of all foragers and old bees. Only experienced precocious foragers and 4-week-old bees, however, displayed an additional proliferation of segments of intermediate branch order. Experienced precocious foragers therefore not only underwent the initial components of mushroom body reorganization prematurely but also continued to develop at a more rapid pace so that at just $10 \mathrm{~d}$ of age they were indistinguishable from 4-week-old bees.

These results also provide evidence that increasing age is correlated with increasing complexity of Kenyon cell dendrites. P7 bees had less complex dendrites, as well as smaller neuropil volumes, than did any other group of bees, including D1 adults. Significant outgrowth of Kenyon cell dendrites occurred in 2 d, without the acquisition of flight experience. Postnatal dendritic development such as this has been well documented in neurons of the mammalian cortex, particularly in the months immediately after birth (Cupp and Uemura, 1980; Juraska, 1982; Koenderink et al., 1994; Zec and Tieman, 1994).

Although previous studies used 1-d-old adults as an endpoint for comparisons of neuropil volumes, this study began analysis at day 7 of the pupal stage. Our results show that extensive dendritic outgrowth and neuropil expansion occur in the mushroom bodies between day 7 of the pupal stage and adult eclosion $2 \mathrm{~d}$ later and continues throughout the first part of adult life. Thus, the addition of late pupae to the time line of mushroom body development in the adult provides a more complete representation of the ontogeny of the process, which does not begin abruptly at day 1 of adult life.

Surprisingly, newly emerged 1-d-old adult bees had undergone unexpectedly extensive branching at the distal tips of the den-
A
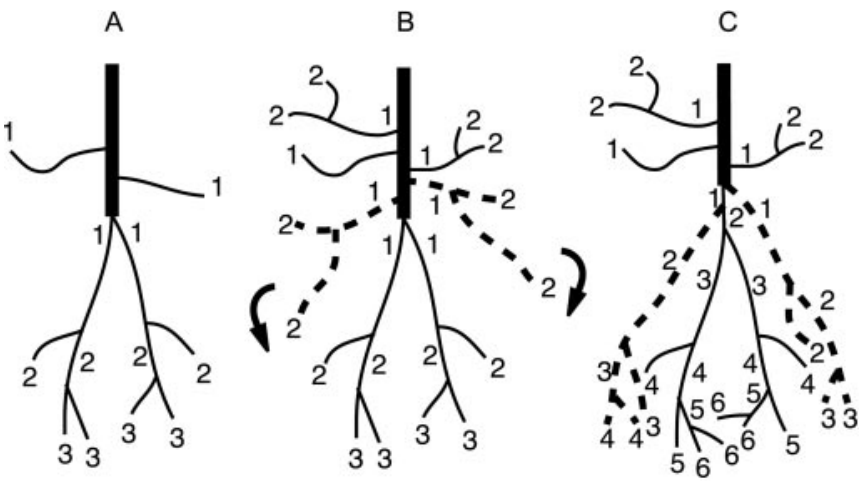

Figure 10. Schematic diagram representing how branch order distribution patterns observed in nurses, new precocious foragers, and experienced precocious foragers may be achieved by experience-dependent dendritic sprouting. New precocious foragers appear to have more dendrites projecting from the main neurite than do nurses and experienced precocious foragers (dotted lines). Experienced precocious foragers appear to lose these main neurite dendritic projections, with a subsequent increase in higher branch orders. This progression could be explained if some of the new branches seen in precocious foragers continued branching toward the calyx base instead of perpendicular to the neurite (dotted lines), causing the main branch point to shift upward. Branching at distal tips also contributes to the increase in the number of higher-order branches seen in experienced precocious foragers. Numbers indicate branch orders of each dendritic segment.

dritic tree. This extra branching was not seen in nurse bees from the same source colony sampled at $10 \mathrm{~d}$ of age, despite the fact that, as expected, they displayed larger neuropil volumes than 1-d-old adults. The reason for this branching and subsequent retraction is not clear.

Two earlier studies presented evidence that age and foraging experience affect Kenyon cell dendritic morphology in honeybees, specifically at the level of dendritic spines. Coss et al. (1980) observed that there is a gradual shortening of the spine stem from 1 day of age to the onset of foraging. A subsequent study (Brandon and Coss, 1982) indicated that a single orientation flight resulted in a significant shortening of Kenyon cell dendritic spines. The limitations of the experimental methods used in these studies, however, prevent definitive conclusions. The differences in spine stem length or head width indicated are close to, or even below, the limits of resolution using the reported methods of visualization. Higherresolution measurements are necessary to clarify the relationship between dendritic spine morphology and experience in the honeybee provocatively suggested by these studies.

In the present study, no difference in dendritic spine density was observed in any of the behavioral groups, regardless of age or foraging experience. Dendritic spines are the primary locations of synaptic contact between the dendritic tree and afferent neurons (Harris and Kater, 1994), so it is assumed that more synapses are formed by neurons with more total dendritic spines. If the total dendritic surface of a neuron is increasing (by the lengthening of existing branches and the addition of new branches), the maintenance of a constant spine density indicates that the total spine number is also increasing. Expansion of the dendritic field would allow a cell to make more contacts with afferent neurons or to establish connections with altogether different neurons. Such an increase in total synaptic surface area would thus serve to strengthen the capacity of the adult brain to function under conditions of novel or enriched sensory stimuli (outside the hive vs inside the hive) or in learning and memory formation (for 
example, the association of floral cues with food rewards and learning the landscape features around the hive entrance).

Experience and the neuroanatomical modifications that occur as a result are associated with increased behavioral functioning. Rats raised in enriched environments undergo dramatic changes in the morphology of cortical neurons and display an increased ability to solve complex problems (for review, see Rosenzweig and Bennett, 1996). The effects of increasing age and foraging experience on dendritic outgrowth in the honeybee mushroom bodies mirrors the results obtained in studies of vertebrates. Differences in rearing conditions for rodents can be directly compared with the transition from in-hive tasks to foraging. A new forager will experience a massive increase in visual stimulation and flight activity as well as the need for spatial orientation and learning and memory relative to what it experiences in the dark hive. The insect mushroom bodies, like the mammalian cortex and hippocampus, are implicated in learning and sensory integration. The expansion of dendritic fields via lengthening and branching of the dendrites thus appears to be a phylogenetically widespread mechanism by which a brain may accommodate increasing levels of sensory information and learning, either as a result of increasing age or experience.

\section{REFERENCES}

Bertholf LM (1925) The moults of the honeybee. J Econ Entomol 18:380-384.

Brandon J, Coss R (1982) Rapid dendritic spine shortening during onetrial learning: the honeybee's first orientation flight. Brain Res 252:51-61.

Bullock TH, Horridge GA (1965) Structure and function in the nervous systems of invertebrates. San Francisco: Freeman.

Burrows M (1996) The neurobiology of an insect brain. New York: Oxford UP.

Capaldi EA, Smith AD, Osborne J, Fahrbach SE, Farris SM, Reynolds DR, Edwards AS, Martin A, Robinson GE, Poppy GM, Riley JR (2000) Ontogeny of orientation flight in the honeybee revealed by harmonic radar. Nature 403:537-540.

Coss RG, Brandon JG, Globus A (1980) Changes in morphology of dendritic spines on honeybee calycal interneurons associated with cumulative nursing and foraging experience. Brain Res 192:49-59.

Cupp CJ, Uemura E (1980) Age-related changes in prefrontal cortex of Macaca mulatta: quantitative analysis of dendritic branching patterns. Exp Neurol 69:143-163.

Diamond MC, Rosenzweig MR, Bennett EL, Lindner B, Lyon L (1972) Effects of environmental enrichment and impoverishment on rat cerebral cortex. J Neurobiol 3:47-64.

Durst C, Eichmuller S, Menzel R (1994) Development and experience lead to increased volume of subcompartments of the honeybee mushroom body. Behav Neural Biol 62:259-263.

Fahrbach SE, Robinson GE (1995) Behavioral development in the honey bee: toward the study of learning under natural conditions. Learn Mem 2:199-224.

Fahrbach SE, Giray T, Robinson GE (1995) Volume changes in the mushroom bodies of adult honey bee queens. Neurobiol Learn Mem 63:181-191.

Fahrbach SE, Moore D, Capaldi EA, Farris SM, Robinson GE (1998) Experience-expectant plasticity in the mushroom bodies of the honey bee. Learn Mem 5:115-123.

Farris SM, Fahrbach SE, Robinson GE (1995) Effects of behavioral reversion on brain structural plasticity in the honey bee. Soc Neurosci Abstr 21:458.

Farris SM, Robinson GE, Davis RL, Fahrbach SE (1999) Larval and pupal development of the mushroom bodies in the honey bee, Apis mellifera. J Comp Neurol 414:97-113.

Ganeshina O, Shafer S, Malun D (2000) Proliferation and programmed cell death of neuronal precursors in the mushroom bodies of the honeybee. J Comp Neurol 417:349-365.

Greenough WT, Volkmar FR (1973) Pattern of dendritic branching in rat occipital cortex after rearing in complex environments. Exp Neurol 40:491-504.

Greenough WT, Larson JR, Withers GS (1985) Effects of unilateral and bilateral training in a reaching task on dendritic branching of neurons in the rat motor-sensory forelimb cortex. Behav Neural Biol 44:301-314.

Gundersen HJG, Jensen EB (1987) The efficiency of systematic sampling in stereology and its prediction. J Microsc 147:229-263.
Gundersen HJG, Bendtsen TF, Korbo L, Marcussen N, Møller A, Nielsen K, Nyengaard JR, Pakkenberg B, Sorensen FB, Vesterby A, West MJ (1988) Some new, simple and efficient stereological methods and their use in pathological research and diagnosis. APMIS 96:379-394.

Hammer M, Menzel R (1995) Learning and memory in the honeybee. J Neurosci 15:1617-1630.

Harris KM, Kater SB (1994) Dendritic spines: cellular specialization imparting both stability and flexibility to synaptic function. Annu Rev Psychol 17:341-371.

Heisenberg M, Heusipp M, Wanke C (1995) Structural plasticity in the Drosophila brain. J Neurosci 15:1951-1960.

Huang Z-Y, Robinson GE (1992) Honey bee colony integration: Worker-worker interactions mediate hormonally regulated plasticity in the division of labor. Proc Natl Acad Sci USA 89:11726-11729.

Huang Z-Y, Robinson GE (1996) Regulation of honey bee division of labor by colony age demography. Behav Ecol Sociobiol 39:147-158.

Huang Z-Y, Robinson GE, Tobe SS, Yagi KJ, Strambi C, Stay B (1991) Hormonal regulation of behavioral development in the honey bee is based on changes in the rate of juvenile hormone biosynthesis. J Insect Physiol 37:733-741.

Juraska J (1982) The development of pyramidal neurons after eye opening in the visual cortex of hooded rats: a quantitative study. J Comp Neurol 212:208-213.

Klüver H, Barrera E (1953) A method for the combined staining of cells and fibers in the nervous system. J Neuropathol Exp Neurol 12:400403

Koenderink MJTh, Uylings HBM, Mrzljak L (1994) Postnatal maturation of the layer III pyramidal neurons in the human prefrontal cortex: a quantitative Golgi analysis. Brain Res 653:173-182.

Kolb B, Whishaw IQ (1998) Brain plasticity and behavior. Annu Rev Psychol 49:43-64.

Kolb B, Forgie M, Gibb R, Gorny G, Rowntree S (1998) Age, experience and the changing brain. Neurosci Biobehav Rev 22:143-159.

Li YS, Strausfeld NJ (1997) Morphology and sensory modality of mushroom body extrinsic neurons in the brain of the cockroach, Periplaneta americana. J Comp Neurol 387:631-650.

Michel RP, Cruz-Orive LM (1988) Application of the Cavalieri principle and vertical sections method to lung: estimation of volume and pleural surface area. J Microsc 150:117-136.

Mobbs PG (1982) The brain of the honey bee Apis mellifera L. The connections and spatial organization of the mushroom bodies. Philos Trans R Soc Lond B Biol Sci 298:309-354.

Møller A, Strange P, Gundersen HJG (1990) Efficient estimation of cell volume using the nucleator and dissector. J Microsc 159:61-71.

Robinson GE (1987) Regulation of honey bee age polyethism by juvenile hormone. Behav Ecol Sociobiol 20:329-338.

Robinson GE (1992) Regulation of division of labor in insect societies. Annu Rev Entomol 37:637-665.

Robinson GE, Page RE (1988) Genetic determination of guarding and undertaking in honey-bee colonies. Nature 333:356-358.

Robinson GE, Page RE, Strambi C, Strambi A (1989) Hormonal and genetic control of behavioral integration in honey bee colonies. Science 246:109-112.

Rosenzweig MR, Bennett EL (1996) Psychobiology of plasticity: effects of training and experience on brain and behavior. Behav Brain Res 78:57-65.

Sholl DA (1953) Dendritic organization in the neurons of the visual and motor cortices of the cat. J Anat 87:387-407.

Siegel S (1956) Nonparametric statistics for the behavioral sciences. New York: McGraw-Hill.

Spinelli DN, Jensen FE, Viani di Prisco G (1980) Early experience effect of dendritic branching in normally reared kittens. Exp Neurol 68:1-11.

Technau GM (1984) Fiber number in the mushroom bodies of adult Drosophila melanogaster depends on age, sex, and experience. J Neurogenet 1:113-126.

Uylings HBM, Kuypers K, Veltman WAM (1978) Environmental influences on neocortex in later life. Prog Brain Res 48:261-274.

Volkmar FR, Greenough WT (1972) Rearing complexity affects branching of dendrites in the visual cortex of the rat. Science 176:1445-1447.

West MJ (1993) New stereological methods for counting neurons. Neurobiol Aging 14:275-285.

Winston ML (1987) The biology of the honey bee. Cambridge, MA: Harvard UP.

Winston ML, Katz SJ (1982) Foraging differences between crossfostered honey bee workers (Apis mellifera) of European and Africanized races. Behav Ecol Sociobiol 10:125-129.

Withers GS, Fahrbach SE, Robinson GE (1993) Selective neuroanatomical plasticity and division of labour in the honeybee. Nature 364:238-240.

Withers GS, Fahrbach SE, Robinson GE (1995) Effects of experience and juvenile hormone on the organization of the mushroom bodies of honey bees. J Neurobiol 26:130-144.

Zec N, Tieman SB (1994) Development of the dendritic fields of layer 3 pyramidal cells in the kitten's visual cortex. J Comp Neurol 339:288-
300 . 